\title{
HISTÓRIA ORAL E HISTÓRIA DA EDUCAÇÃO: O QUE REVELAM AS MEMÓRIAS DE DOCENTES E DISCENTES ${ }^{1}$
}

Clarice de Quadro ${ }^{2}$

André Paulo Castanha ${ }^{3}$

\begin{abstract}
Resumo: O presente texto é resultado das pesquisas desenvolvidas na modalidade de Iniciação Científica entre 2016 e 2017, no projeto "História Oral e História da Educação Regional: as memórias de docentes e discentes entre 1950 e 1990", cujo lócus da pesquisa se concentra em Francisco Beltrão e região. Diante das precárias condições de manutenção dos acervos documentais, entre eles, os mantidos pelos poderes públicos e instituições escolares; diante da despreocupação que muitas instituições têm com a memória histórica, cabe a nós dedicarmos esforços no sentido desenvolvermos ações para preservar a memória ainda existente. Nesse sentido, realizamos entrevistas com exprofessores e ex-alunos visando compreender a dinâmica do trabalho docente e da organização escolar da época. As entrevistas seguiram a metodologia e os procedimentos da História Oral. $\mathrm{O}$ uso das fontes ajudou a entender o funcionamento e o desenvolvimento da educação ao longo do tempo, trazendo contribuições à educação atual, possibilitando um aprimoramento aos futuros educadores que estão em formação.

Palavras-Chave: Memória Docente, História Oral, Francisco Beltrão, Educação Regional

\section{ORAL HISTORY AND HISTORY OF EDUCATION: WHAT DISCOVER THE MEMORIES OF TEACHERS AND DISCIPLES}

\begin{abstract}
The present text is a result of the research developed in the modality of Scientific Initiation between 2016 and 2017, in the project "Oral History and History of Regional Education: the memories of teachers and students between 1950 and 1990", whose locus of research focuses on Francisco Beltrão and region. Faced with the precarious conditions of maintenance of documentary collections, among them, those maintained by public authorities and school institutions; in the face of the unconcern that many institutions have with historical memory, it is up to us to dedicate our efforts to develop actions to preserve the memory that still exists. In this sense, we conducted interviews with ex-teachers and former students to understand the dynamics of teaching work and the school organization of the time. The interviews followed the Oral History methodology and procedures. The use of the sources helped to understand the functioning and development of education over time, bringing contributions to current education, enabling an improvement to future educators who are in training.
\end{abstract}

Key words: Teaching Memory, Oral History, Francisco Beltrão, Regional Education

\section{Introdução}

O presente texto é resultado das pesquisas desenvolvidas na modalidade de Iniciação Científica entre 2016 e 2017, com o projeto "História Oral e História da Educação Regional: as memórias de docentes e discentes entre 1950 e 1990”. Esse projeto se configura como um subprojeto de um projeto amplo, denominado de: "Problematizando as fontes da e/ou para a História da Educação brasileira nos séculos XIX e XX: do nacional ao local”, cujo objetivo é fazer um amplo levantamento, problematização e interpretando fontes referentes a educação.

\footnotetext{
${ }^{1}$ Texto produzido a partir dos resultados da pesquisa de Iniciação Científica intitulada: "História Oral e História da Educação Regional: As Memórias de Docentes e Discentes Entre 1950 e 1990”, desenvolvida entre agosto de 2016 e julho de 2017, junto ao programa de Iniciação Científica da Universidade Estadual do Oeste do Paraná - UNIOEST. A pesquisa foi financiada pela Fundação Araucária.

${ }^{2}$ Graduada em Pedagogia pela Universidade Estadual do Paraná - Campus de Francisco Beltrão, não de 2017.

${ }^{3}$ Professor do Colegiado de Pedagogia e do Mestrado em Educação da UNIOESTE - Campus de Francisco Beltrão - PR. Membro do Grupo de Pesquisa: História, Sociedade e Educação no Brasil - HISTEDOPR - GT local do HISTEDBR. E-mail: andrecastanha66@gmail.com
} 
A região Sudoeste do Paraná, na qual estamos inseridos, é relativamente nova se tomarmos como referência a história do Paraná e do Brasil. Entretanto, pouco conhecemos sobre essa história, pois grande parte dela tem sido perdida em função da ausência de acervos documentais que possibilitem sua preservação e/ou reconstrução. Como indicado por Sbardelotto e Castanha (2018), os estudos sobre a história da educação na região ainda são poucos.

Diante das precárias condições de manutenção dos acervos documentais, entre eles, os mantidos pelos poderes públicos e instituições escolares na região; diante da despreocupação que muitas instituições têm com a memória histórica, cabe a nós dedicarmos esforços no sentido de desenvolvermos ações para preservar a memória ainda existente. Assim, o objetivo do projeto foi/é constituir um acervo de fontes, produzidas a partir da metodologia da História Oral, sobre memória docente e discente, mediante a coleta de depoimentos de professores que atuaram em Francisco Beltrão e região entre as décadas de 1950 e 1990. Nosso propósito, neste texto, é revelar, a partir desses depoimentos traços das práticas pedagógicas, das condições de trabalho e da formação dos docentes que atuaram na região.

Para alcançar o objetivo deste estudo foi necessário compreender os procedimentos da história oral. O que ela pode trazer de contribuição para a história da educação? Qual a sua importância para o resgate histórico? Qual deve ser nossa postura perante os entrevistados? Para isso se fez um estudo teórico sobre o desenrolar da história oral, buscando perceber como ela elabora suas memórias e organiza suas narrativas, como ela desenvolve outro olhar referente à história, construindo uma história do presente com intenção de estudos presentes e futuros.

O recorte delimitado teve como base o início da década 1950, período no qual temos registros da implantação das escolas rurais e urbanas em nossa região, financiada e mantida pela Colônia Agrícola Nacional General Osório (CANGO) ou pelo município de Francisco Beltrão, como indicou Cattelan (2014). Por meio de entrevistas realizadas com educadores/estudantes que atuaram naquela época procuramos conhecer um pouco mais do processo educacional do período. Nesse sentido, realizamos entrevistas com ex-professores e ex-alunos visando compreender a dinâmica do trabalho docente e da organização escolar da época. As entrevistas seguiram a metodologia e os procedimentos da História Oral.

O texto está fundamentado em estudos bibliográficos e em depoimentos e está organizado em três partes. Na primeira tratamos suscintamente dos objetivos e dificuldades da coleta de depoimentos; em seguida das bases teóricas e metodológicas da História Oral e, posteriormente dos dados obtidos com os entrevistados. 


\section{Objetivos, Procedimentos e Dificuldades da Coleta de Depoimentos}

Almejamos, a partir do desenvolvimento desta pesquisa produzir novos conhecimentos sobre a história da educação regional e estimular futuras pesquisas. Essa fonte, aliada a documentação, abre novas possibilidades de novas análises da história da educação regional. Esse tratamento deve nos permitir um posicionamento crítico em relação ao debate historiográfico, facilitando, assim, uma delimitação mais consequente do trabalho de pesquisa em História e, no nosso caso particular, em História da Educação regional.

O objetivo da pesquisa constituiu-se em buscar evidências sobre a construção do processo histórica educacional, que permitiu a estruturação das escolas que atuaram na época, compreendendo os desafios enfrentados nas questões pedagógicas e administrativas articuladas aos aspectos sociais, econômicos, políticos, históricos e culturais que alicerçam esse processo e como essas ações se manifestavam no dia a dia com os alunos, sua compreensão/visão dos fatos nessa época.

Buscamos também a preservação e recuperação da memória histórica, que é uma das condições indispensável, tanto para a produção de novos conhecimentos, quanto para evitar a mera reprodução de determinadas "verdades" consagradas pela historiografia educacional circulante. Nesse sentido, o projeto levantou, catalogou e problematizou fontes referentes à história da educação local e regional, tendo como base a memória dos professores/alunos e a documentação preservada por eles.

Registramos as experiências e representações destes indivíduos, que estão inseridos em determinado contexto social, possibilitando novas visões da história ao dar voz às "multidões", um resgatar da história local proporcionado por meio das lembranças dos sujeitos que vivenciaram essa época. Um registro voluntário das recordações desse passado num esforço intelectual do indivíduo, possibilitando a reinterpretação do passado, uma história alternativa a história oficial, uma visão de quem presenciou e viveu esse período.

Conforme indicou Castanha (2008), o processo de resgate das fontes da e/ou para a história da educação amplia as possibilidades de compreensão do fenômeno educativo, pois a educação é um componente fundamental das relações sociais que está presente em todas as dimensões da vida social do sujeito. Assim, a reconstrução histórica de um determinado período ou de determinadas experiências sociais depende essencialmente das fontes, que são o ponto de origem, a base e o ponto de apoio para a produção historiográfica que se pretende enfatizar.

Conforme indicado por Lopes e Galvão, o uso dessa metodologia pode apresentar alguns inconvenientes. 
[...] a utilização da história oral, muitas vezes considerada simples pelos pesquisadores, propõe, na verdade, uma série de problemas. Inicialmente, destacam-se, a imprevisibilidade e o não-controle da situação, o que requer do pesquisador a disposição e a habilidade para a escuta. Em muitos casos, é necessário relativizar as respostas dadas pelos entrevistados. Sabe-se que a memória é seletiva, que os depoimentos mudam no decorrer do tempo, que muitas vezes os entrevistados falam o que imaginam que devem falar para aquele interlocutor específico, sobre o qual criam certas expectativas e ao qual atribuem determinados valores (2001, p. 89).

As dificuldades indicadas pelas autoras estão ligadas a realização da entrevista e ao conjunto de informações que os depoimentos podem apresentar. Nós encontramos além dessas outro tipo de dificuldade.

Devido a limitação do acesso as fontes documentais, visto que não dispomos de arquivos organizados, a opção pelas entrevistas se constitui em uma excelente opção de levantamento de dados. Todavia, essa metodologia encontra algumas dificuldades devido à resistência dos depoentes. Na região, por ser de colonização bastante recente, temos muitas pessoas que vivenciaram os primeiros anos da colonização da região e que foram alunos ou professores nas décadas de 1950, 1960 e 1970. No entanto, o fato de haver muitos possíveis depoentes, não significa que a pesquisa não encontra dificuldades de efetivação. Nós tivemos bastante dificuldades no decorrer do desenvolvimento do projeto para conseguir contato com os docentes e discentes, dispostos a conceder entrevistas. Ao identificar os depoentes e fizermos o primeiro contato, percebíamos um certo entusiasmo com a possibilidade de serem ouvidos, mas, quando entravámos em contato novamente para agendar a entrevista, muitos arrumaram desculpas para não agendar, alegando não disporem de tempo, devido aos compromissos cotidianos da casa, trabalho, viagem etc. Depois de algumas tentativas não darem certo entendíamos que não havia mais o desejo pelo depoimento.

A resistência em falar é muito comum na história oral, como indicou Freitas (2002). Os depoentes ficam receosos com os objetivos dos pesquisadores. Muitas vezes tem medo do uso que será feito de suas memórias ou, em alguns casos, consideram suas memórias sem qualquer relevância para a história. Daí a necessidade de ter o devido cuidado no contato com os depoentes e no uso das memórias coletadas.

\section{Os Pressupostos Teóricos e Metodológicos da História Oral}

A História Oral é um método de pesquisa que utiliza como principal meio para obter as informações que necessita, as técnicas de entrevista. Seu objetivo é recolher depoimentos, 
testemunhos, promover análises de processos sociais do presente, para assim facilitar, conhecer o meio imediato em que se está focado o desenvolvimento da observação, o registro da narrativa das experiências humanas relatadas. Conforme foi definida por Allan Nevis como a "moderna história oral", devido ao uso de recursos eletrônicos, ela é técnica e fonte, por meio das quais se produz conhecimento (MEIHY, 2015, p. 103).

Constatamos que a História Oral agrega um expressivo valor a história do tempo presente, ela dá voz às multidões, que antes não tinham voz ativa na história, na qual estavam inseridas, mas que agora fazem parte fundamental da mesma.

A memória é uma prerrogativa do ser humano e é produzida/armazenada através dos tempos por sujeitos reais e não por estruturas que determinam sua vida, mas que apenas influem em algumas decisões, que o mesmo tomou ou posso vir a tomar, ou perceber a relação estabelecida pelas pessoas e o mundo em que vivem. A história oral se constitui assim em um instrumento metodológico que pode captar essas memórias e possibilitar uma prática reflexiva que aspira melhor concretização e compreensão dos valores e do processo a que as mesmas foram produzidas. Segundo Verena Alberti,

[...] a entrevistas de história oral é resíduo de uma ação específica, qual seja, a de interpretar o passado. Note-se que, se chamo isso de ação é porque estou indo um pouco além da constatação inicial de que a entrevista é uma construção do passado. Tomar a entrevista como resíduo de ação, e não apenas como relato de ações passadas, é chamar a atenção para a possibilidade de ela documentar as ações de constituição de memórias - as ações que tanto o entrevistado quanto o entrevistador pretendem estar desencadeando ao construir o passado de uma forma e não de outra $(2004$, p. 35).

É cada vez mais comum o uso de entrevistas por profissionais que atuam nos meios de comunicação da atualidade. As entrevistas realizadas por esses profissionais não podem ser confundidas com história oral, elas visam somente esclarecer, elucidar algum assunto ou ponto de vista de alguns envolvidos em certa questão, pois essas entrevistas, geralmente são marcadas pela superficialidade em todos os pontos, não existindo um aprofundamento do conhecimento a respeito da questão que se está discutindo. Os entrevistadores, em sua maioria, não têm como foco aprofundar conhecimentos, assim, as entrevistas não têm por objetivo o aprofundamento do conhecimento por parte do entrevistador.

Não existe um conceito fechado de história oral, o que existe são várias definições a cerca dessa metodologia de pesquisa, ela tem como principal finalidade criar fontes históricas que possam vir a ser utilizadas como fonte de pesquisa no presente e futuro do sujeito que assim desejar. Desta forma, os depoimentos devem ser armazenados, conservados e a sua abordagem 
inicial deve partir da definição precisa do objeto de pesquisa, o que se quer estudar, observar, deve existir um aprofundamento/conhecimento sobre o que se deseja trabalhar. Para ser considerada história oral, inicialmente deve se ter um projeto desenvolvido, claramente formulado, como indicam Mehiy (2005) e Barros 2005), ou seja, com toda a explicação de como serão as observações, entrevistas, enfim, todo o andamento da pesquisa. Um projeto de história oral pode ser desenvolvido individualmente ou como trabalho coletivo. Conforme destacou Meihy:

História oral é um conjunto de procedimentos que se iniciam com a elaboração de um projeto e que continuam com a definição de um grupo de pessoas (ou colônia) a ser entrevistada. O projeto prevê: planejamento da condução das gravações; transcrição; conferência da fita com o texto; autorização para uso; arquivamento e, sempre que possível, publicação dos resultados, que devem em primeiro lugar, voltar ao grupo que gerou as entrevistas (2005, p.18).

A moderna história oral foi desenvolvida para dar as narrativas que eram passadas de pai para filhos, de geração para geração, as experiências, seus preceitos e ensinamentos transmitidos pela oralidade, um caráter científico ou "histórico". As entrevistas sempre estiveram presentes, mas não no caráter e forma da atualidade, era uma forma mais informal de pesquisa, não possuíam a tecnologia, nem os equipamentos eletrônicos que se utilizam hoje para realizar as mesmas. Somente após a segunda guerra mundial é que a história oral começou a atribuir critérios que as diferenciaram das formas consagradas de entrevista, com suas próprias especificidades. Ao adotar uma metodologia clara, a história oral tornou os depoimentos colhidos como fontes para a compreensão do passado, ao lado de documentos escritos, imagens e outros tipos de registro existentes auxiliando no desenvolvimento da pesquisa.

As fontes produzidas pela História Oral caracterizam-se por serem produzidas a partir de um estímulo/assunto, pois o pesquisador procura o entrevistado e lhe faz perguntas, geralmente depois de consumado o fato/assunto que se quer investigar. Além disso, fazem parte de todo um conjunto de documentos do tipo biográfico, ao lado de memórias e autobiografias, que permitem compreender como os sujeitos experimentaram, interpretaram/interpretam os acontecimentos, situações e modos de vida de um grupo ou da sociedade, em que estavam/estão inseridos no momento estudado. Isso torna o estudo da história mais concreto e próximo, facilitando a apreensão do passado pelas gerações futuras e a compreensão das experiências vividas por outros.

Segundo Meihy (2005), a primeira experiência da história oral como uma atividade organizada foi em 1948 em Nova York pelo professor Allan Nevis. O boom da história oral nos 
Estados Unidos, deu-se no final dos anos 1960 inícios dos anos 1970, mas foi Paul Thompson na Grã-Bretanha que se tornou uma das principais autoridades na reflexão e utilização desse método para o registro histórico. Seu livro A voz do passado é considerado um clássico. Conforme indicou Meihy, nesse livro, Paul Thompson afirma que a história oral é tão velha quanto à própria história, tem a definição de moderna por fazer uso de métodos que consistem na realização de depoimentos pessoais orais, por meio da técnica que utiliza um gravador, além de estratégias, questões práticas e éticas relacionadas ao uso do mesmo. Nesse sentido, Meihy destacou:

Ainda que muitos se valham do conceito de história oral para qualquer forma de entrevista, modernamente ela só é assim considerada se decorrente de um projeto que reconheça sua intenção, determine os procedimentos e a devolução publica dos resultados (2005, p. 92).

Já no Brasil a primeira experiência ocorreu no Museu da Imagem e do Som em São Paulo, em 1971. No Paraná essa experiência ocorreu em 1972, no Museu do Arquivo Histórico da Universidade de Londrina, mas a experimentação mais importante e incentivadora tem sido a do Centro de Pesquisa e Documentação de História Contemporânea do Brasil - CPDOC, com sua fundação em 1975. Ainda se percebe uma grande resistência no âmbito acadêmico com relação à história oral, mas isso ocorre devido à tardia penetração da história oral no Brasil e a influência do positivismo. Devido ao golpe militar de 1964 a história oral teve um atraso se comparado com outros países, que começou a se desenvolver de forma mais coesa após os anos 1980 e, principalmente nos anos 1990. Com esse avanço passou a ser mais vista nos meios acadêmicos como outra forma de registrar os fatos que ocorrem na sociedade, pontos de vista diferentes e uma agregação de valores aos fatos já consolidados, com caráter internacional e multidisciplinar, ela possui um caráter revolucionário, de certa forma, pois vem agregar aos documentos já existentes mais um meio de registro da nossa história. Já houve muitas classificações para a expressão história oral. Alguns já a classificaram como método, técnica e teoria, no entanto, há um consenso no meio acadêmico em classificar a mesma como uma metodologia de pesquisa.

Lucien Febvre afirmou: “A história faz-se com documentos escritos, sem dúvida. Quando eles existem. Mas ela pode fazer-se sem documentos escritos, se os não houver" (Febvre, 1989, p. 95). A história oral também fornece documentação para reconstruir o passado recente, que também é histórico, ela legitima a história do presente, pois, a história sempre foi vista como 
algo do passado, que estuda o que está muito longe de nossa realidade, a história oral vem para produzir documentação diferenciada e alternativa da história do presente.

Essa metodologia de pesquisa histórica ainda é pouco conhecida, mas de suma importância para resgatar uma parte da história que ficou de certa forma, oculta no decorrer dos anos. A história oral parte da reflexão teórico-metodológica à prática do trabalho de campo, da entrevista e transcrição do arquivamento e conservação. O uso da História Oral, bem como das narrativas que dela se originam, estimulam a escrita de uma História que não é uma representação exata do que existiu, mas que se esforça em propor uma inteligibilidade, em compreender a forma como o passado chega até o presente. O que o historiador escreve não é aquilo que se passou expressamente e, sim, uma produção discursiva.

Se constituiu em outra maneira de escrever a história, é um trabalho que se aprende fazendo/desenvolvendo. Uma das características da história oral é suas qualidades práticas, o envolvimento pessoal, a disposição em confrontar-se diretamente com a realidade do campo que se pesquisa. Essa pesquisa em história oral possibilita reflexões sobre o registro dos fatos na voz dos próprios protagonistas sobre suas histórias. A metodologia utilizada em história oral para a apropriação do conhecimento é própria.

Conforme destacado por Julio Aróstegui (2006), a pesquisa histórica surge de "achados", desenvolve-se com a utilização de novas fontes de pesquisa, de novas conexões entre elas, de comparações, releituras, ou de inquietações com os acontecimentos ou explicações existentes, insatisfações que, por sua vez, são provocadas pelo aparecimento de novos pontos de vista, de novas "teorias", ou de novas formas de trabalhar com a documentação existente e que deseja descobrir. Daí a necessidade de o historiador se preocupar com o modo como articular sua pesquisa, levando em consideração as fontes, a organização das informações, a tipologia e seu uso, assim como a relação com outras pesquisas da mesma área, ou similares.

Temos consciência de que não existe neutralidade do pesquisador, pois é ele quem escolhe o tipo de entrevista ou qualquer outro instrumento de coleta de dados ou fontes, por isso, seu ponto de vista está presente. Assim, é preciso respeitar os princípios éticos e de objetividade na pesquisa, lembrando que nenhum método dá conta de captar os problemas em todas as suas dimensões e especificidades. Todas as conclusões são provisórias, pois podem ser aprofundadas e revistas por pesquisas posteriores, não podem ser consideradas prontas e acabadas.

O pesquisador não deve se apropriar da entrevista somente como uma técnica de coleta de dados, mas como parte integrante da construção do objeto de estudo que se está realizando. A entrevista compreensiva não tem uma estrutura rígida, isto é, as questões previamente definidas 
podem sofrer alterações conforme o direcionamento que se quer dar à investigação e com o andamento das perguntas, podendo aparecer outras perguntas dependendo das respostas dadas. Na História Oral, mesmo na temática, é preciso dar preferência a perguntas mais abertas e seguir um roteiro flexível, no qual, o sujeito entrevistado consiga se expressar de uma forma mais confortável. Também é importante reservar um tempo relativamente longo para a realização da entrevista para um aproveitamento maior da entrevista.

O levantamento realizado pela metodologia da história oral visa o registro de experiências e representações dos indivíduos que estão inseridos em determinada época e contexto social. A história oral possibilita novas visões da história ao dar voz às "multidões", um resgate da história local por meio da memória histórica. Esse método possibilita o registro voluntário das recordações desse passado num esforço intelectual do indivíduo, possibilitando a reinterpretação do passado, ou seja, constitui-se em alternativa a história oficial.

Como nos indica Mehiy (2005), a entrevista é uma troca de experiências entre duas pessoas, o entrevistador deve começar com uma pergunta para situar o entrevistado, para que o mesmo não se sinta perdido em suas próprias lembranças. A entrevista somente espontânea não existe, cabe ao entrevistador saber o quanto deve perguntar e se aprofundar no assunto em questão, o que vai depender das reações do entrevistado ao que foi lhe perguntado. Uma regra básica em história oral é que nunca deve se interromper uma fala do entrevistado e não demonstrar desinteresse pela conversa. Um instrumento fundamental para o pesquisador em história oral é capacidade de saber ouvir. O local da entrevista deve ser determinado pelo entrevistado, deve ser um local onde o colaborador se sinta à vontade para relatar os fatos que corroboram para a pesquisa que está em desenvolvimento. A entrevista não deve ultrapassar duas horas de duração para que não ocorra uma exaustão das partes. Segundo Meihy, o “'Colaborador' é um termo importante na definição do relacionamento entre o entrevistador e o entrevistado. Sobretudo, é fundamental porque estabelece uma relação de compromisso entre as partes" (2005, p.124).

Segundo Garrido, "a interdependência entre prática, metodologia e teoria produz o conhecimento histórico; mas é a teoria que oferece os meios para refletir sobre esse conhecimento, embasando e orientando o trabalho dos historiadores, aí incluídos os que trabalham com fontes orais" (1993, p. 33). Ou seja, a História Oral une metodologia e prática, auxiliando na produção de fontes orais sem escapar dos rigores científicos que a disciplina histórica requer e exige, mas sem descuidar, da análise teórica sobre a fonte produzida. 


\section{O Conteúdo das Entrevistas: uma Síntese Analítica}

O método utilizado em nossa pesquisa foi a História Oral. Os materiais utilizados para a obtenção de dados para a construção desse texto foram fontes bibliográficas e as entrevistas das seguintes professoras:

Quadro 1. Relação de professoras entrevistadas com indicação do ano de início e fim da docência.

\begin{tabular}{|l|c|c|}
\hline Nome & Iniciou Atuação Docente & Término da Atuação Docente \\
\hline Clídia Lorenzetti Klosinski. & 1952 & 1982 \\
\hline $\begin{array}{l}\text { Celita Natalina Priamo } \\
\text { Reolon. }\end{array}$ & 1954 & 1984 \\
\hline Inez de Oliveira Santos. & 1968 & 2014 \\
\hline Fátima Missio Seleski. & 1975 & 2005 \\
\hline
\end{tabular}

Fonte: entrevistas. Dados organizado pelos autores.

Quadro 2. Relação de ex-alunos entrevistadas com indicação do ano de início da escolarização.

\begin{tabular}{|l|l|}
\hline Nome & Início da atuação discente \\
\hline Maria Isabel Camargo de Oliveira & Ano de 1954 \\
\hline Jandira Paiano & Ano de 1965 \\
\hline Jucemara Kosloviski Picolotto & Ano de 1977 \\
\hline
\end{tabular}

Fonte: entrevistas. Dados organizado pelos autores.

Para melhor visualizar o contexto de trabalho e de iniciação discente das entrevistadas organizamos as entrevistas por ano em que atuaram/estudaram, para facilitar a análise. Fizemos também a leituras de artigos e livros para fundamentação da pesquisa e ajudar na interpretação e compreensão do momento histórico, bem como da legislação para compreender a organização da educação no período.

Ao desenvolver as entrevistas com os docentes percebemos uma forte ligação entre os depoimentos, enfatizando que as leis educacionais que regiam a educação na época eram de um certo rigor, onde todos tinham que seguir o mesmo cronograma dentro das escolas, a fiscalização 
era contínua e sempre presente no meio escolar, a pedagogia tradicional era muito forte, os castigos eram presentes, muito empregados na prática pedagógica da sala de aula.

As professoras Clídia e Celita entrevistadas que atuaram nos primeiros períodos aos quais estamos trabalhando declararam que em seu primeiro ano de atuação como professoras trabalharam sem receber salário, por "amor as crianças". As professoras lecionavam em escolas improvisadas em igrejas, porões e casas cedidas pelas pessoas da comunidade. Como indicou Cattelan (2014) foi somente a partir de 1954 que o município iniciou a construção de casas escolares nas comunidades rurais.

As professoras relataram que as condições de trabalho eram difíceis, com salas superlotadas de crianças, salas multisseriadas, com poucas condições de ensinar adequadamente. Conforme previa a legislação que regia o ensino primário da época, cabia ao professor ensinar:

I. Leitura e linguagem oral e escrita. II. Iniciação matemática. III. Geografia e história do Brasil. IV. Conhecimentos gerais aplicados à vida social, à educação para a saúde e ao trabalho. V. Desenho e trabalhos manuais. VI. Canto orfeônico. VII. Educação física (BRASIL, Decreto 8.529 de 1946, Art. $7^{\circ}$ ).

Diante de tantas responsabilidades, entrevistadas ressaltaram que o trabalho nas escolas só se realizava devido a participação dos pais e da comunidade.

As avaliações aplicadas no dia a dia eram de responsabilidade dos professores regentes, mas a avaliação que definia se os alunos passavam de ano era elaborada e aplicado por um professor de outra escola ou pelo inspetor municipal ou estadual. Cabia aos inspetores fazer a fiscalização das escolas, estes faziam visitas constante nas escolas, muitas vezes pegando as professoras de surpresa.

Os professores eram os responsáveis pelo cuidado da escola, pelo seu funcionamento, pelas matrículas, pela limpeza, pelos materiais, pela preparação da merenda. Mesmo com tanto trabalho e responsabilidades, as professoras declaram "Amávamos o que fazíamos".

As professoras Clídia e Celita enfatizaram que recebiam alguma formação continuada para realizar o trabalho, mas que quando começaram a dar aula não tinham a formação exigida pela legislação. Conforme estabelecia o artigo 34 da Lei Orgânica do ensino primário de 1946, "O magistério primário só pode ser exercido por brasileiros, maiores de dezoito anos, em boas condições de saúde física e mental, e que hajam recebido preparação conveniente, em cursos apropriados, ou prestado exame de habilitação, na forma da lei”. O artigo 35, definia que os poderes públicos deveriam providenciar o "contínuo aperfeiçoamento técnico do professorado 
das suas escolas primárias" (BRASIL, Decreto 8.529, de 1946). Segundo as professoras eram ofertados cursos todos os anos com participação obrigatória de todos os professores.

As necessidades de formação levaram muitas professoras a cursar a Escola Normal Regional ou Ginasial e a Escola Normal Colegial, que, conforme Belliato e Castanha (2016), funcionaram junto ao Instituto Nossa Senhora da Gloria, entre 1959 e 1973.

As professoras Inez e Fátima, já atuaram mais em escolas urbanas e em uma época onde as escolas já estavam melhor estruturadas, com local próprio, com condições melhores de trabalho. A responsabilidade dos professores ficava mais com os alunos e não com toda a escola. Nessas escolas, as salas já eram divididas por faixa etária e por séries, menos alunos por turma, as avaliações eram aplicadas pelas professoras que ensinavam em sala, ou seja, as condições nesse período já eram melhores que no início da atuação de professores na região.

Conforme previsto pelo artigo 17, da Lei de Diretrizes e Bases do Ensino de $1^{\circ} \mathrm{Grau}$, Lei 5.692, de 1971, "O ensino de $1^{\text {o }}$ grau destina-se à formação da criança e do pré-adolescente, variando em conteúdo e métodos segundo as fases de desenvolvimento dos alunos" (BRASIL, Lei n. 5.692, de 1971). Essa lei tornou obrigatório o ensino de $1^{\mathrm{a}}$ a $8^{\mathrm{a}}$ série (entre 7 e 14 anos). Nessa época, as escolas urbanas já funcionavam de forma seriada, na zona rural ainda funcionavam de forma multisseriadas, mas era ofertado apenas o ensino de $1^{\mathrm{a}}$ a $4^{\mathrm{a}}$ séries.

Nos depoimentos, as professoras destacaram as mudanças na forma de participação dos pais e alunos ao longo dos anos, sendo no início mais ativa e presente a ação dos pais. Com o passar dos anos, os pais foram diminuindo a participação e os alunos passaram a serem mais indisciplinados, ou seja, os professores passaram a ser desrespeitados pelos alunos e, consequentemente foram perdendo a autoridade em sala da aula.

As entrevistas com as ex-alunas Maria Isabel e Jandira Paiano revelaram situações similares, mas sob outra ótica. Quem iniciou na década de 1950 revelou que a escola no período funcionava com turmas muito numerosas, com vários níveis de aprendizagem. Relatou também a prática de castigos físicos e psicológicos por parte dos professores. Nessa época, a professora era quem tomava conta de todas as funções da escola, mas os alunos ajudavam em várias atividades, como limpeza, os maiores cobravam as lições dos menores etc. Nos depoimentos foram ressaltadas as dificuldades que enfrentavam para chegar na escola. O deslocamento das crianças era feito a pé, sendo difícil, devido as condições das estradas com muita lama. Nos depoimentos também ficou evidente que os pais apoiavam os professores no controle da disciplina em sala, ou seja, consideravam e valorizavam a autoridade do professor. 
Nos depoimentos foi enfatizado algumas dificuldades que as famílias enfrentavam, levando os pais a permitir que boa parte das crianças estudasse somente até a $4^{\text {a }}$ série, pois precisavam da ajuda das crianças maiores, em vários trabalhos domésticos ou na lavoura.

Já no caso da entrevistada Jucemara, que estudou nos anos 1977 ficou evidente algumas diferenças no funcionamento e organização das escolas. Na época, as escolas funcionavam com salas separadas, cada criança em seu nível de aprendizagem, o estudo era mais valorizado pelos pais que incentivavam a continuação dos estudos, a valorização dos professores ainda era presente, a participação dos pais também. Nessa época já era possível cursar o ensino de $2^{\circ}$ Grau sem sair de Francisco Beltrão.

O conteúdo das entrevistas aqui consideradas revelou práticas do cotidiano escolar que possivelmente não encontraríamos em outros suportes, como, por exemplo, o uso de castigos físicos e psicológicos no ensino primário como meio para disciplinar a criança, mesmo depois de proibido legalmente, as crianças que deixam os estudos para ajudar no sustento da família, entre outros. Há relatos que revelam como se dava a visita dos inspetores às escolas e como eram realizadas as reuniões pedagógicas. Sobre a visita de inspetor, as professoras que lecionavam para o ensino primário, revelam o medo que sentiam no momento da visita do inspetor em sua escola, pois sabiam que estavam sendo avaliada pelos mesmos.

Observamos que os relatos são mais esmiuçados e as histórias mais animadas, quando os entrevistados docentes falam de sua vida escolar como estudante. Ocorre o oposto quando falam de sua vida como professoras: algumas memórias demonstram desânimo, mais seriedade, cansaço, talvez desesperança. As discentes, por sua vez, demonstram como era sofrida a vida nessa época, como era difícil conseguir estudar, como sentem falta de ter parado de estudar na infância, mesmo que algumas voltaram a estudar depois de adultas e tenham terminado os estudos e até mesmo conseguido uma formação, mas relatam que gostariam de ter continuado os estudos na infância.

O desenvolvimento dessa pesquisa se mostrou de suma importância devido a grande contribuição que as entrevistas trouxeram a compreensão de como eram aplicadas as leis estabelecidas pelo estado na época em questão, de como essas aplicações eram percebidas pelos alunos e professores que viveram nessa época. Com o desenvolvimento desta pesquisa produzimos novos conhecimentos sobre a história da educação regional e desencadeamos fatos que poderão alimentar futuras pesquisas na área da educação que emerge cada dia com mais interesse em aprendizagem. 
Converter as memórias de alguém em palavras e trabalhá-las é uma função que merece cautela e atenção por parte do entrevistador. Os sentimentos tornam-se mais intensos e podem interferir nas lembranças relatadas. Com as observações realizadas se percebeu uma cautela em certos relatos, demonstrando por meio de olhares e gestos que não se sentiam à vontade em falar sobre o determinado assunto que estava em discussão. Na maioria das entrevistas foi relatado sobre as formas de castigos que se aplicavam na época, percebeu-se que não queriam falar sobre o assunto, relatavam que não havia castigos corporais somente educacionais, mas logo mudavam de assunto. Percebemos assim, que o assunto não era muito receptivo para as entrevistadas (docentes).

\section{Conclusões}

Concluímos que a história oral vem para ser mais uma ferramenta no auxílio da busca por respostas as questões que ficam no ar por falta de fontes. Ela possibilitou a visão de pessoas que vivenciaram as situações, ajudando a perceber como as mudanças na prática educativa tem mudado de forma lenta. A partir do olhar de quem vivenciou essa época, ficou mais evidente as condições que as professoras tinham e as dificuldades pelas quais passaram ao longo dos anos para conseguirem atuar como educadoras nas escolas primárias, como as regras que observamos nas leis impostas pelo estado que aparecem nos livros e artigos estudados, o que realmente postas em prática e quais consequências, caso não fossem aplicadas corretamente na sala de aula.

Percebemos neste ponto a importância da história oral para os registros dos acontecimentos não somete do passado distante, mas também do presente, da fase contemporânea, uma forma de garantir a história daqueles que não tem história registrada, mas as mantém em suas memórias fatos, experiências vivenciadas. Somente com o registro é que essas memórias podem se constituir em conhecimento acumulado ou base para produzir conhecimento. Com isso pode se ter o ponto de vista de outros ângulos, não somente daqueles que estão registrados nos livros, ou seja, se tem a oportunidade de conhecer a história vivenciada por aqueles que estiveram, participaram dessa fase, podendo assim ter a noção de como foi a experiência de viver em determinada época com determinadas regras/leis.

Os dados obtidos na pesquisa revelam as dificuldades encontradas pelos professores e alunos, tanto estruturais, de locomoção, como pedagógicas naquele período. Nesse sentido, a pesquisa e as leituras realizadas ao longo do desenvolvimento a pesquisa reforçam a importância do levantamento e catalogação dos documentos educacionais, das vivências, das dificuldades enfrentadas. Essas fontes ajudam a entender o funcionamento e o desenvolvimento da educação 
ao longo do tempo, extraindo as boas práticas e as contribuições à educação atual, possibilitando um aprimoramento aos futuros educadores que estão em formação. As fontes documentais e orais revelam o desenrolar da prática baseada nas leis de cada período, pelo qual a educação passou, abrindo novos caminhos para a pesquisa.

Concluímos assim que a história oral vem como um complemento das diversas formas de história, vem para acrescentar uma dinâmica diferente de fazer história, dar voz ativa as multidões que antes não tinham participação muito atuante nas questões referentes às histórias que eram contadas.

A prática de pesquisa com fontes orais está em concordância com aquilo que se espera de quem entende a história oral como metodologia, pois implica reflexão teórica, trabalho empírico e de campo, um processo de constituição de uma fonte e, principalmente, um processo de produção de conhecimentos científicos. Portanto, a utilização de fontes orais na pesquisa em história não se limita apenas a chamada história dos "excluídos", mas permite ampliar as fontes que o historiador tem a sua disposição para produzir conhecimentos históricos sobre realidades nem sempre valorizadas ou problematizadas até o presente momento.

Eis o desafio, articular a teoria e a metodologia da História Oral, para produzir fontes para a história da educação regional, possibilitando, assim o avanço do conhecimento histórico.

\section{Referências}

ALBERTI, Verena. Manual de História Oral. Rio de Janeiro: FGV, 2004.

ARÓSTEGUI, J. A pesquisa histórica: teoria e método. Bauru: Edusc, 2006.

BARROS, José D'Assunção. O projeto de pesquisa em História: da escolha do tema ao quadro teórico. Petrópolis: Vozes, 2005.

BELliATO, Moacir da Costa e CASTANHA, André Paulo. Escola Normal Colegial Estadual Regina Mundi - 1965 - 1976: primeiros apontamentos sobre a formação de professores primários em Francisco Beltrão-PR. Faz Ciência, vol. 18, n. 27, jan/jun de 2016, p. 191-211.

BRASIL. Decreto-Lei no 8.529, de 2 de janeiro de 1946. Lei Orgânica do Ensino Primário. Rio de Janeiro: Diário Oficial da União - Seção 1 - 4/1/1946, p. 113 (Coleção de Leis do Brasil 1946, Vol. 1).

BRASIL. Lei $n^{\circ} 5.692$, de 11 de agosto de 1971. Fixa Diretrizes e Bases para o ensino de $1^{\circ}$ e $2^{\circ}$ graus, e dá outras providências. Brasília. Coleção de Leis do Brasil de 1971, vol. 5. Publicado no Diário Oficial da União - Seção 1 em 12/8/1971, p. 6377

CASTANHA, André Paulo. As fontes e a problemática da pesquisa em história da educação. In: ORSO, Paulino José et al. (Orgs). História da educação: levantamento de fontes e instituições escolares. Cascavel-PR: Coluna do Saber, 2008, p. 15-27.

CATTELAN, Carla. Educação Rural no Município de Francisco Beltrão entre 1948 e 1981: a escola multisseriada. 248 f. dissertações de Mestrado em Educação. Francisco Beltrão (Mestrado). Centro de Ciências Humanas, Universidade Estadual do Oeste do Paraná, 2014. 
FEBVRE, Lucien. Combates pela História. 3 ed. Lisboa: Editorial Presença, 1989.

FREITAS, Sônia Maria de. História Oral: possibilidades e procedimentos. São Paulo: Imprensa oficial do estado SP, 2002.

GARRIDO, loan del Alcazar As fontes orais na pesquisa histórica: uma contribuição ao debate. Revista Brasileira de História. São Paulo, v. 13, n. 25/26, set92-ago/93.

LOPES, Eliana Marta Teixeira e GALVÃO, Ana Maria de Oliveira. História da Educação. Rio de Janeiro: DP\&A Editora, 2001.

MEIHY, José Carlos Sebe Bom. História Oral: como fazer, como pensar/ José Carlos Sebe Bom Meihy, Fabiola Holanda. $2^{\text {a }}$ ed. São Paulo: Contexto, 2015.

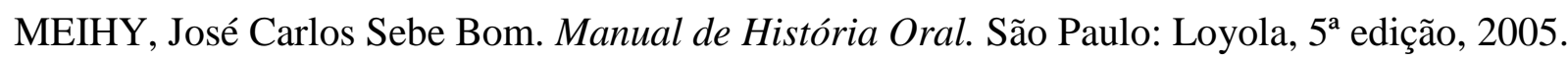

SBARDELOTTO, Denise Kloeckner e CASTANHA, André Paulo. A pesquisa em história da educação no Sudoeste do Paraná: análise e perspectiva. Revista de História e Historiografia da Educação. Curitiba, Brasil, v. 2, n. 4, p. 189-213, janeiro/abril de 2018. 